\title{
Corporate social behaviour: Is it good for efficiency in the Chinese banking industry?
}

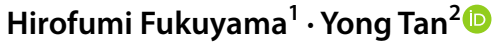

Accepted: 11 February 2021 / Published online: 26 February 2021

(c) The Author(s) 2021

\begin{abstract}
We develop an output-oriented data envelopment analysis framework to examine the efficiency of Chinese banks over the period 2007-2017 and further test the relationship between efficiency and corporate social responsibility (CSR). We are the first piece of research considering the number of employees as one bank input and potential increase in the number of employees as one CSR indicator. Additionally, we innovatively propose another three specific CSR indicators: namely donation, balance of green credits and loans to small and medium sized enterprises. The results show that the gain from improving allocative output-efficiency by reallocating variable inputs is less than the gain attained by improving technical output-efficiency. Evidence from the second-stage regression analysis shows that the overall indirect technical efficiency is significantly and negatively affected by the volumes of green credits, while an increase in the volumes of donations will improve the indirect allocative efficiency.
\end{abstract}

Keywords DEA $\cdot$ Chinese banks · Corporate social responsibility · Bank risk · Bootstrapped truncated regression

JEL Classification $\mathrm{C} 14 \cdot \mathrm{G} 21 \cdot \mathrm{C} 24$

\section{Introduction}

Nowadays, the banking industry, in particular the Chinese banking industry, earns a huge amount of profits through its traditional deposits and loans services and a variety of noninterest generating activities. The efficient allocation of resources is of great concern to different parties in society; this is related to the internal banking operation. More and more

Yong Tan

a.y.tan@hud.ac.uk

Hirofumi Fukuyama

fukuyama@fukuoka-u.ac.jp

1 Faculty of Commerce, Fukuoka University, 8-19-1 Nanakuma, Jonan-Ku, Fukuoka 814-0180, Japan

2 Department of Accounting, Finance and Economics, Huddersfield Business School, University of Huddersfield, Huddersfield, Queensgate HD1 3DH, UK 
banks now realize that the successful operation of a bank does not depend solely on its internal management, but it also depends on its external activities, through which banks provide returns to society by engaging in different types of activities, contributing to the development of the economy, environment and the society. Such corporate social responsibility (CSR) is thought to have a significant impact on bank reputation and bank image. Although quite a few empirical studies have investigated the CSR issues and their impact on bank financial performance, there is no study considering CSR and their impact on efficiency in the Chinese banking context. Moreover, all the studies use very general indicators to measure CSR in the banking sector and no attempt has been made to propose and use specific indicators that are closely related to CSR.

When looking at corporate social behaviour undertaken by the Chinese commercial banks, we need to consider the types of activities they engage in. In general, the types of CSR can be classified into four groups: firstly, the corporate social behaviour undertaken by the Chinese commercial banks can contribute to the positive development of the society and economy by alleviating the unemployment problem. Through employing more staff, both at the managerial level and administrative level, the banks are able to help the economy by improving employment levels and contribute to the development of the society by alleviating the unemployment issue. Secondly, not only can the CSR promote equal economic development among different geographical areas and, in particular, provide support to the development of poor areas in China, but it can also further enhance the development of important sectors of the economy. More specifically, this behaviour can be reflected by providing donations to the "Hope Programme", which targets the western areas, where students cannot afford to undertake education. In addition, donations were given to universities for their scholarship and research development. Thirdly, the corporate social behaviour can further protect the environment. To be more specific, the Chinese commercial banks have been gradually increasing their awareness of and concern about the importance of a cleaner environment for the economy, and they have incentivized different companies or projects engaging in environmental protection activities by providing credits. These pollution free credits granted by the Chinese commercial banks are also called "Green Credits". Finally, the CSR undertaken by the Chinese commercial banks can promote an equal development of different types of enterprises in China. As argued by Tan (2017), Chinese commercial banks allocated a large volume of credits to the large and state-owned enterprises in China, while it is relatively difficult for the small and medium sized enterprises (SMEs) to get loans from the Chinese commercial banks. According to Elliott et al. (2015), the SMEs in China provided $70 \%$ of employment and contributed $60 \%$ of China's GDP in 2012; however, they only received $30 \%$ of bank loans. The incentive and behaviour engaged in by the Chinese commercial banks to provide more credits to SMEs in China will not only benefit sound and balanced development among different types of enterprises in China but will also significantly contribute to economic growth.

The selection of CSR variables is in line with the framework provided by Scholtens (2009) to assess international banks' CSR. The framework focused on four different aspects of CSR in the banking industry: (1) codes of ethics, sustainability reporting, and environmental management system; (2) environmental management; (3) responsible financial products; (4) social conduct. Different indicators are used to measure each of these four aspects. We argue that potential increase in the number of employees and loans to SMEs are in line with the indicator "Diversity and Opportunity" under the "social conduct" category. More specifically, we argue that potential increase in the number of employees will provide more opportunities to people who are looking for a job, and this will also reduce the unemployment rate for the economy. As discussed above, the SMEs find it very 
difficult to get bank loans; providing loans to them will provide more opportunities for them to engage in investments and further contribute to the economic growth in China. Our proposal of using donations as one variable of CSR is in line with the indicator "community involvement" under the category of "social conduct". Finally, our proposal of using green credits as one CSR variable is in accordance with the indicator "sustainable financing" under the category of "responsible financial products".

The current paper contributes to the empirical banking literature mainly in the following ways: firstly, we contribute to the efficiency measurement in the banking industry by proposing a framework to analyze the efficiency level of Chinese commercial banks using an indirect distance function incorporating a corporate social responsibility variable; more specifically, we provide the first piece of research to propose the number of employees as one input and the potential increase in the number of employees as the CSR indicator. Secondly, we propose and use three indicators focusing on three-specific aspects of CSR from three perspectives, namely donations (social perspective), balance of green credits (environmental perspective) and loans to SMEs (economic perspective) and investigate their impacts on bank efficiency. This is also the first piece of research investigating the impacts of these three proposed CSR on bank efficiency under the Simar and Wilson (2007) Bootstrapped truncated regression.

The findings show that the gains obtained by improving the technical output-efficiency are more than the ones attained by improving the allocative output efficiency through reallocating variable inputs. Most importantly, we find that the Chinese banking industry can enhance its social responsible behaviour through employing more staff to alleviate the unemployment issue for the economy. The second stage analysis reports that among the proposed three different CSR indicators, donations is significantly and positively related to indirect allocative efficiency, while the overall indirect technical efficiency is significantly and negatively affected by balance of green credits.

The paper is structured as follows: Sect. 2 reviews the literature on efficiency and corporate social responsibility in the banking sector. Section 3 explains the methodology. Section 4 presents the data and choice of model, and then Sect. 5 reports the results. Section 6 presents the additional robustness check. Section 7 provides a discussion of the results. Finally, a conclusion and discussion on policy implications are given in Sect. 8.

\section{Literature review}

\subsection{Efficiency in the Chinese banking industry}

There are a number of studies investigating the efficiency level of Chinese commercial banks under SFA (Jiang et al., 2013; Sun \& Chang, 2011; Sun et al., 2013 and Dong et al. 2016; among others). The results from Jiang et al. (2013) show that state-owned commercial banks have the lowest level of efficiency compared to other ownership types and banking sector reforms are helpful in improving the efficiency level of Chinese banks. The rest of the studies show that the efficiency level in the Chinese banking industry is affected by diversification, risk level, bank size, market power, bank listing and strategic investors.

Using a stochastic meta-frontier framework, Huang and Fu (2013) investigate the determinants of cost frontier gap between Chinese and Taiwanese banks over the period 2005-2009. The authors find that this gap is mainly determined by financial market structure, institutional environment and political development. The study also identifies 
that Taiwanese banks do not only have a lower cost frontier, but also a lower level of cost efficiency. In particular, foreign banks in China are found to have the highest cost efficiency and private banks in Taiwan to have the minimum cost frontier. Their findings also suggest that, in contrast to Taiwanese banks, Chinese banks should reduce their size of operation.

A second branch of studies uses DEA to evaluate efficiency in the Chinese banking industry (An et al., 2015; Asmild \& Matthews, 2012; Avkiran \& Morita, 2010; Du et al., 2018; Fu et al., 2016; Shi et al., 2017; Wang et al., 2014; Yu et al., 2019; Zha et al., 2016; Zhou et al., 2018). The results show that the Chinese banking industry should carefully reconsider the scale of operation, although the studies do not reach a consensus regarding the comparison of efficiency level among different ownership types of banks. The findings suggest that the efficiency of Chinese banks is mainly from the deposit production process. Regarding the determinants of efficiency in the Chinese banking industry, the findings show that the efficiency of Chinese banks is significantly affected by bank risk, share of other earning assets, share of non-earning assets, total equity and financial reforms. Finally, it is suggested that lower level of efficiency is attributed to weak risk control and Chinese commercial banks can benefit from a proposed merger.

Besides the studies on Chinese banking efficiency from the international academic journals as reviewed above, many studies on the same topic were published in the Chinese domestic economics and finance journals. Liu and Song (2004) use stochastic frontier analysis approach to evaluate the X-efficiency and scale efficiency of four state-owned and 10 shareholding banks over the period 1996-2001. The findings suggest that listed shareholding banks have higher X-efficiency than unlisted ones and state-owned banks. In addition, the results show that shareholding banks exhibit economies of scales and state-owned banks experience diseconomies of scale. Instead of using stochastic frontier analysis approach, Yang and Zhang (2007) use the data envelopment analysis to assess the level of cost efficiency and profit efficiency for a sample of Chinese banks between 1996 and 2005. The findings report that Chinese commercial banks are different in the level of cost efficiency and profit efficiency, although the level of these two efficiencies of joinstock banks are lower than that of state-owned banks, and the improvement of the former is quicker than the latter. Using the same method as Yang and Zhang (2007), Song et al. (2009) received a different result, showing that state-owned banks are less efficient than joint-stock banks. Not only testing the efficiency levels in the Chinese banking industry, $\mathrm{Xu}$ and Shi (2006) use both the stochastic frontier analysis and data envelopment analysis to evaluate the efficiency of 14 commercial banks between 1997 and 2001. Although the results generated from these two different methods produce efficiency scores with a big difference, they also showed they have a good coincidence.

Yao et al. (2004) focus on the efficiency analysis, and also applied the stochastic frontier analysis for the efficiency evaluation of 22 Chinese banks over the period 1995-2001. They further examine the impacts of ownership structure and hard budget constraints on bank efficiency. The results show that non-state-owned banks are $8-11 \%$ more efficient than state-owned banks and banks facing harder budget constraints perform better than the ones that are supported by the government. A slacks-based directional distance function is used by Wang and Zhu (2011) to investigate the efficiency level in the Chinese banking industry. The findings indicate that (1) joint-stock commercial banks outperform the state-owned commercial banks; (2) the main sources of inefficiency are from non-interest income and non-performing loans; (3) the macroeconomic environment, including the shares of foreign banks and monetary supply growth, are significantly related to bank efficiency. 


\subsection{Corporate social responsibility and performance}

There are few studies investigating the issue of the relationship between CSR and corporate performance (Ciciretti et al., 2014; Mallin et al., 2014; Platonova et al., 2018; Simpson \& Kohers, 2002; Soana, 2011; Zhu et al., 2017; among others). All the studies measure the performance in the banking sector using relevant accounting ratios, and although Ciciretti et al. (2014) examine the efficiency level and the impact of CSR on efficiency, the general community reinvestment act is used to measure the CSR. Zhu et al. (2017) further extend the study of Ciciretti et al. (2014) by using social contribution value per share to measure the CSR. This indicator suffers from the limitation that only listed banks will be applicable and unlisted banks are ignored. There are few pieces of research investigating the impact of CSR on risk level (Harjoto and Laksmana, 2016; Hsu and Chen, 2015; Oikonomou et al., 2012; Albuquerque et al., 2019). However, all the studies focus on non-financial institutions. There are few studies which attempted to examine the relationship between CSR and bank risk (Bolton, 2013; Gambetta et al., 2017; Gangi et al., 2018; among others). Our study significantly contributes to the literature on CSR in banking by being the first piece of research using three specific indicators (namely donations, Loans to Small and Medium Sized Enterprises and Balance of Green Credits) related to banks' corporate social behaviour rather than general CSR indices or scores (Francis et al., 2018). This is supposed to generate important policy implications to the banking regulatory authority. Also we use number of employees as one input and also propose the potential increase in the number of employees as one CSR indicator.

\subsection{Hypothesis development}

As argued previously, we are going to be the first piece of research measuring corporate social responsibility in the banking industry by using four explicit indicators, including increase in employment, donations, loans to small and medium sized enterprise and balance of green credits.

Increase in the level of employment in the banking industry will, from the macroscopic level, reduce the employment rate and alleviate the poverty of the country. While from the microscopic level, this will increase the bank burden by increasing banks' personnel expenses. However, a larger number of employees in the banking institution will increase the possibility of innovation activities and potential of generating more ideas to optimize bank production process, which will further improve bank efficiency. Therefore, our first hypothesis will be:

we do not have any a priori expectation with regard to the impact of the increase in the number of employees on bank efficiency.

Donations, as discussed previously, will not only promote the quality and quantity of research activities engaged in by the universities, but will also contribute to the equal economic development between different parts of China. On the other hand, this obviously will increase banks non-interest expenses; however, this will promote the bank image and increase bank brand awareness. Consequently customers, companies and depositors will be more likely to do business with the bank, and the increase in the volume of business engaged in by the bank will reduce bank cost and further improve bank efficiency. Therefore, our second hypothesis is: 
we do not have any a priori expectation in terms of the impact of donations on bank efficiency.

Thirdly, loans to small and medium sized enterprises will provide a fairer development for different types of enterprises in China and will further increase the contributions of small and medium sized enterprises to the country's economy. On the one hand, granting credits to small and medium-sized enterprises will increase bank risk due to the fact that they are holding a smaller amount of capital and do not have any government support, thus increasing bank cost in terms of risk monitoring, checking and management. On the other hand, allocating credits to both large and small and medium sized enterprises will not only increase the volumes of loan businesses engaged in by the banks, but also increase the "type" of loan businesses engaged in by the banks. The cost will be reduced derived from the economies of scale and economies of scope. Therefore, our third hypothesis will be: we do not have any a priori expectation with regard to the impact of loans to small and medium sized enterprises on bank efficiency.

Finally, balance of green credits mainly reflects banks' corporate social responsibility from the perspective of their commitment to protecting the environment from the businesses they are conducting. From the microeconomic level perspective, green projects normally have a higher level of default risk (Baker et al., 2018; Partridge \& Medda, 2020). This would increase bank cost and further reduce bank efficiency. On the other hand, if regulation effectively incentivises this type of credit, and competition for this market segment consolidates, then its effect on bank efficiency can turn positive (Schaeck \& Cihák, 2014). Therefore, our fourth hypothesis is:

we do not have any a priori expectation with regards to the impact of balance of green credits on bank efficiency.

\section{Methodology}

\subsection{Production theoretic preliminaries}

Let $x=\left(x_{1}, \ldots, x_{n}, \ldots, x_{N}\right) \in \Re_{+}^{N}$ and $y=\left(y_{1}, \ldots, y_{m}, \ldots, y_{M}\right) \in \mathfrak{R}_{+}^{M}$ be non-negative vectors of $\mathrm{N}$ inputs and $\mathrm{M}$ outputs, respectively. The production process is modeled by the direct output possibility set:

$$
P(x)=\left\{y \mid x \in \mathfrak{R}_{+}^{N} \text { can produce } y \in \mathfrak{R}_{+}^{M}\right\},
$$

which gives all output vectors that can be produced by a given vector of inputs $x$.

We assume that $P(x)$ satisfies strong disposability of inputs and outputs and is convex and compact. The direct output possibility set (1) can alternatively be written as the production possibility set, denoted by

$$
T=\{(x, y) \mid y \in P(x)\} .
$$

Therefore, we have $y \in P(x) \Leftrightarrow \quad(x, y) \in T$. The cost function is defined as

$$
C(y, w)=\min _{x}\{w x \mid y \in P(x)\}=\min _{x}\{w x \mid(x, y) \in T\}
$$


where $w=\left(w_{1}, \ldots, w_{n}, \ldots, w_{N}\right) \in \mathfrak{R}_{++}^{N}$ is a positive vector of $\mathrm{N}$ variable input prices and $w x$ is the inner product, i.e., $w x=w_{1} x_{1}+\cdots+w_{n} x_{n}+\cdots+w_{N} x_{N}$. Following Shephard (1974), we define the indirect (budget-constrained) output possibility set as

$$
I P(w / c)=\{y \mid \text { There is } x \geq 0 \text { such that } y \in P(x) \text { and } w x \leq c\}
$$

where $c$ is a positive prescribed input cost or budget. The indirect output possibility set, $I P(w / c)$, gives the set of all output vectors that can be produced at a cost not greater than $c$, while the inputs are endogenously determine in Eq. (4). Since the cost function is by definition homogeneous of degree 1 in input prices, i.e., $C(y, \alpha w)=\alpha C(y, w), \forall \alpha>0$, Eq. (4) can be written as

$$
I P(w / c)=\{y \mid C(y, w) \leq c\}=\{y \mid C(y, w / c) \leq 1\} .
$$

The two output possibility sets, $P(x)$ and $I P(w / c)$ are related as follows:

$$
P(x) \subseteq I P(w / c) \text { for }(w / c) x \leq 1 \text { and } \bigcup_{(w / c) x \leq 1} P(x)=I P(w / c)
$$

See Färe and Primont (1995) for Eq. (6). Relative to the direct output possibility set, $P(x)$, the direct (radial) output distance function is defined by

$$
\frac{1}{D_{O}(x, y)}=\sup _{\varphi}\{\varphi \mid \varphi y \in P(x)\},
$$

which is a complete characterization of the output possibility set (1) in the sense that

$$
D_{O}(x, y) \leq 1 \text { if and only if } y \in P(x) .
$$

We defined the direct technical efficiency, $T E$, as being equal to the direct output distance function, i.e.,

$$
T E=D_{O}(x, y)
$$

If $T E=1$, then a bank is technically efficient. If $T E<1$, then the firm is technically inefficient. Relative to $I P(w / c)$, defined in (4), the indirect (budget-constrained) output distance function, $I D_{O}(w / c, y)$, is defined for $w / c>0$ as:

$$
\frac{1}{I D_{O}(w / c, y)}=\sup _{\varphi}\{\varphi \mid \varphi y \in I P(w / c)\}
$$

where

$$
I D_{O}(w / c, y) \leq 1 \text { if and only if } y \in I P(w / c) .
$$

Similar to $D_{O}(x, y)$, the indirect output distance functions completely characterize the budget-constrained output possibility set and we define the indirect technical efficiency measure, ITE, as

$$
I T E=I D_{O}(w / c, y) .
$$

A unity value of ITE indicates indirect technical efficiency. If $I T E<1$, then it indicates indirect technical inefficiency. For a more detailed account of direct and indirect production sets and Eq. (6), see Shephard (1970, 1974) and Färe and Primont (1995). 


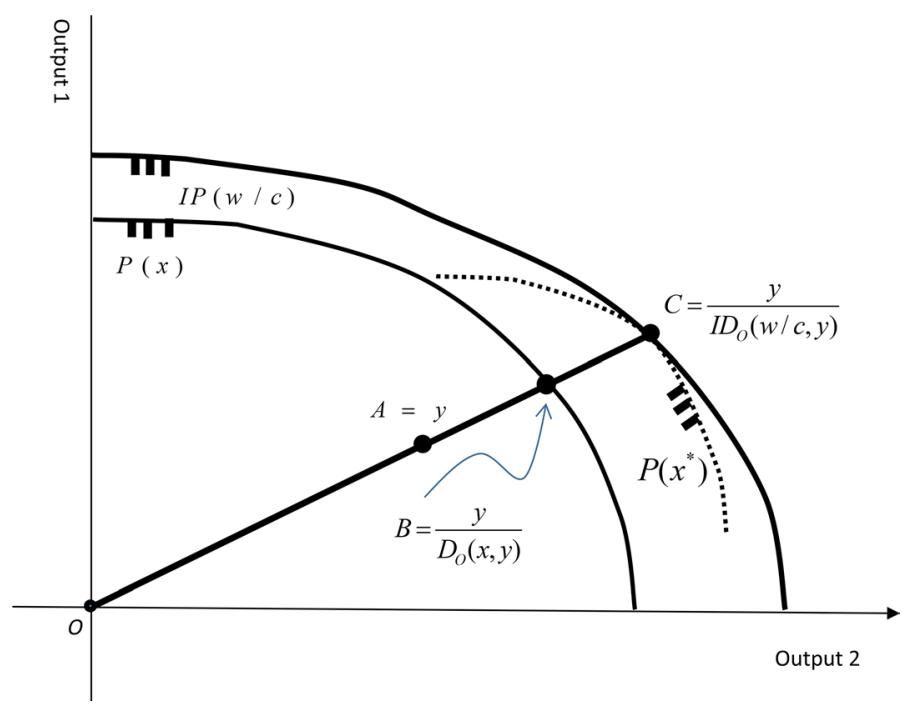

Fig. 1 Direct technical efficiency, indirect technical efficiency and indirect allocative efficiency. Notes: (1) The technical efficiency at $\mathrm{A}(T E)=O A / O B$. (2) The indirect technical efficiency at A $(I T E)=O A / O C$. (3) The indirect allocative efficiency at $\mathrm{A}(I A E)=O B / O C$

Using the two output-efficiency measures, (8) and (10), an indirect allocative efficiency measure, $\operatorname{IAE}(x, w / c, y)$, is denoted as follows:

$$
I A E=\frac{I D_{O}(w / c, y)}{D_{O}(x, y)}=\frac{I T E}{T E} .
$$

The bank could increase all outputs proportionately by $(1-I A E) \times 100 \%$ without any increase in the cost, if allocative inefficiency is removed. Grosskopf et al. (1997) referred to the reciprocal of $I A E$ as the gain function and Fukuyama et al. (1999) defined the gain function as an allocative efficiency measure to study the efficiency of credit cooperatives in Japan. In this article, we define the indirect allocative efficiency as Eq. (11), so that it takes a value between zero and one. It should be noted that, if $(w / c) x \leq 1$ and $y \in P(x)$, then we have that:TE $\leq 1, I T E \leq 1$ and $I A E \leq 1$. It should be noted that,

$$
(w / c) x \leq 1 \text { and } y \in P(x) \Rightarrow T E \leq 1 \text { and } I T E \leq 1 \text { and } I A E \leq 1
$$

From Eq. (11), we arrive at the following decomposition:

$$
I T E=I A E \times T E .
$$

Figure 1 visualizes direct and indirect production possibility sets along with the three output-oriented efficiency measures. Consider the technically inefficient $\mathrm{DMU}_{\mathrm{A}}$, represented by y. Clearly, $y \in P(x)$ and $y \in I P(w / c)$ for $w x \leq c$. Since there is an input vector $x^{*}$ for a given level of $y$, we have that $y \in P\left(x^{*}\right) \subseteq I P(w / c)$ for $w x^{*} \leq c$. The technical efficiency of $\mathrm{DMU}_{\mathrm{A}}$ is calculated as $T E=O A / O B$ and the indirect technical efficiency is obtained as $I T E=O A / O C$. Hence, the indirect allocative efficiency is calculated as $I A E=O B / O C$. The state of output technical efficiency and input allocative efficiency can be reflected by making a comparison between TE and ITE. The maximum technical efficiency regarding outputs can be achieved if $\mathrm{TE}=1$; a bank is allocating inputs efficiently 
but it is not technical efficient if TE $=\mathrm{ITE}<1$. In other words, if this happened, that indicates that reallocating inputs will not lead to any further increase in the output production. A bank is output technical efficient and input allocative efficient if ITE $=\mathrm{TE}=1$. Thus, the input allocative efficiency, IAE, can be measured by the ratio of ITE/TE.

The indirect allocative efficiency (11) is related to, but different from, the standard allocative efficiency measure that is directly constructed based on the cost function (3) and the standard (radial) input distance function $D_{I}(x, y)$ is defined by

$$
\frac{1}{D_{I}(x, y)}=\inf _{\theta}\{\theta \mid y \in P(\theta x)\} .
$$

Using Eqs. (3) and (14), the standard input-oriented allocative efficiency measure, stdAE, is defined as

$$
s t d A E=\frac{C(y, w) / w x}{D_{I}(x, y)}
$$

Note that if $y \in P(x)$ then $s t d A E \leq 1$. The standard input-oriented or input allocative efficiency measure (15) is gauged as the ratio of cost efficiency, $C(y, w) / w x$, to inputoriented technical efficiency, inputTE $=1 / D_{I}(x, y)$. In contrast, the indirect allocative efficiency measure (11) is denoted by the ratio of indirect (output-oriented) technical efficiency, $I D_{O}(w / c, y)$, to direct "output-oriented" technical efficiency $D_{O}(x, y)$.

\subsection{Implementing data envelopment analysis}

Utilizing the preliminaries on indirect production, we develop a DEA (data envelopment analysis) variable returns to scale framework. The term DEA was coined by Charnes et al. (1978) under the assumption of constant returns to scale, and Banker et al. (1984) extended the constant returns to scale model into a variable return to scale variant. Suppose there are $j=1, \ldots, J$ decision making units (DMUs) or banks in our case. Let $x_{n j}$ and $y_{m j}$ represent the observed quantities of inputs and outputs, respectively, for $\mathrm{DMU}_{j}$. Let $\lambda_{j}$ be a non-negative intensity variable for $\mathrm{DMU}_{j}$. The constant returns to scale DEA versions of the direct output possibility set are expressed as

$$
P(x)=\left\{y \mid \begin{array}{l}
\sum_{j=1}^{J} x_{n j} \lambda_{j} \leq x_{n}, \quad n=1, \ldots, N ; \quad \sum_{j=1}^{J} y_{m j} \lambda_{j} \geq y_{m}, \quad m=1, \ldots, M ; \\
\lambda_{j} \geq 0, \quad j=1, \ldots, J
\end{array}\right\}
$$

and the indirect output possibility set is written as

$$
I P(w / c)=\left\{y \mid \begin{array}{l}
\mid \begin{array}{l}
\sum_{j=1}^{J} x_{n j} \lambda_{j} \leq x_{n}, \quad n=1, \ldots, N ; \quad \sum_{n=1}^{N}\left(w_{n} / c\right) x_{n} \leq 1 ; \\
\sum_{j=1}^{J} y_{m j} \lambda_{j} \geq y_{m}, \quad m=1, \ldots, M ; \quad y_{m} \geq 0, \quad m=1, \ldots, M ; \\
x_{n} \geq 0, \quad n=1, \ldots, N ; \quad \lambda_{j} \geq 0, j=1, \ldots, J .
\end{array}
\end{array}\right\}
$$

Relative to Eq. (16), the direct technical efficiency measure is: 


$$
T E=\max _{\varphi, \lambda}\left\{\varphi \mid \begin{array}{l}
\sum_{j=1}^{J} x_{n j} \lambda_{j} \leq x_{n}, \quad n=1, \ldots, N ; \quad \sum_{j=1}^{J} y_{m j} \lambda_{j} \geq \varphi y_{m}, \quad m=1, \ldots, M ; \\
\lambda_{j} \geq 0, \quad j=1, \ldots, J ; \quad \varphi \text { free in sign }
\end{array}\right\}
$$

In (18) the proportional expansion in outputs for the DMU is estimated keeping its fixed and variable input vector constant. Using the technology (17), we obtain the indirect technical efficiency measure as

$$
\frac{1}{I D_{O}(w / c, y)}=\frac{1}{I T E}=\sup _{\varphi, \lambda, x}\left\{\varphi \mid \begin{array}{l}
\sum_{j=1}^{J} x_{n j} \lambda_{j} \leq x_{n}, \quad n=1, \ldots, N ; \quad \sum_{n=1}^{N}\left(w_{n} / c\right) x_{n} \leq 1 ; \\
\sum_{j=1}^{J} y_{m j} \lambda_{j} \geq \varphi y_{m}, \quad m=1, \ldots, M ; \quad \lambda_{j} \geq 0, j=1, \ldots, J ; \\
\varphi \text { free in sign }
\end{array}\right\}
$$

where $c$ is a total cost which is treated as fixed in Eq. (19).

The indirect technical efficiency measure in (19) estimates the proportional expansion in outputs by allowing the DMU to choose variable inputs given current fixed input usage so that the inputs are chosen in such a way that the budget constraint, $\sum_{n=1}^{N} w_{n} x_{n} \leq c_{k}$, is satisfied. The target variable input vector is determined by the solution vector $x^{*}$, where the asterisk * indicates optimality.

\subsection{Simar and Wilson (2007) bootstrapped truncated method to estimate the impact of CSR on bank efficiency}

This study follows the estimation method proposed by Simar and Wilson (2007), who investigate the determinants of bank efficiency using a bootstrap technique. Before illustrating the estimation procedure, the following model is given:

$$
\hat{\delta}_{i}=Z_{i} \beta+\varepsilon_{i}
$$

where $Z_{i}$ is a vector of explanatory variables which are supposed to have impacts on bank efficiency and $\beta$ refers to a vector of parameters with some statistical noise $\varepsilon_{i}$. Simar and Wilson (2007) argue that the advantage of bootstrapped truncated regression lies in the fact that it produces, with bias corrected estimates of $\delta$, valid estimates for the parameters in the regression model.

The bootstrap algorithm is described in the following steps:

1) Calculate the efficiency score $\hat{\delta}$ for each bank in each year using the method described in the previous subsections

2) Use the maximum likelihood method to estimate the truncated regression of $\hat{\delta}$ on $Z_{i}$ to provide an estimate $\hat{\beta}$ of $\beta$ and an estimate $\hat{\sigma}_{\varepsilon}$ of $\sigma_{\varepsilon}$

3) For each bank $\mathrm{i}=1 \ldots \ldots, \mathrm{I}$, repeat the next three steps (a-c) L times to yield a set of bootstrap estimates as $A=\left\{\left(\hat{\beta}^{*}, \hat{\sigma}_{\varepsilon}^{*}\right)_{b}\right\}_{b=1}^{L}$

a. Draw $\varepsilon_{i}$ from the $\mathrm{N}\left(0, \hat{\sigma}_{\varepsilon}^{2}\right)$ distribution with left truncation at $\left(1-\hat{\beta} Z_{i}\right)$. 
Table 1 Summary statistics of the variables used in the efficiency estimation

\begin{tabular}{llllll}
\hline Variables & Observations & Mean & Standard deviation & Minimum & Maximum \\
\hline Interest income & 792 & $8,576,100$ & $2.03 \mathrm{e}+07$ & 790 & $1.39 \mathrm{e}+08$ \\
Non-interest income & 792 & $1,170,670$ & $2,222,337$ & 305 & $1.44 \mathrm{e}+07$ \\
Number of employees & 792 & $36,784.79$ & $90,833.89$ & 101 & 503,082 \\
Fixed assets & 792 & $2,329,888$ & $5,736,235$ & 1008 & $3.80 \mathrm{e}+07$ \\
Total deposits & 792 & $1.78 \mathrm{e}+08$ & $4.32 \mathrm{e}+08$ & 49,098 & $2.95 \mathrm{e}+09$ \\
Price of labour & 792 & 48.02729 & 72.74657 & 0.1312856 & 615.2145 \\
Price of capital & 792 & 1.596175 & 5.841138 & 0.0018114 & 82.71062 \\
Price of funds & 792 & 10.87176 & 62.27033 & 0.00213 & 965.2047 \\
\hline
\end{tabular}

In the efficiency analysis, we consider three inputs, including number of employees, fixed assets and total deposits; two outputs, including interest income and non-interest income, as well as three input prices. The input prices are price of labour, measured by the ratio of personnel expenses to number of employees; price of capital, measured by the ratio of non-interest expenses to fixed assets and the price of funds measured by the ratio of interest expenses to total deposits. All the variables are in RMB 10,000

b. Compute $\delta_{i}^{*}=+\varepsilon_{i}$

c. The maximum likelihood method is used to estimate the truncated regression of $\delta_{i}^{*}$ on $Z_{i}$, yielding estimates $\left(\hat{\beta}^{*}, \hat{\sigma}_{\varepsilon}^{*}\right)$.

4) Use the bootstrap results to construct confidence intervals.

\section{Data and choice of models}

\subsection{Data sources and specification of inputs and outputs}

In terms of the data used in the current study to estimate the efficiency and the impact CSR on bank efficiency, they are mainly collected from Fitch Connect, as well as the annual financial statement from each bank. In total, we collected data for 72 Chinese commercial banks over the period 2007-2017. ${ }^{1}$ More specifically, with regard to the estimation of efficiency in the Chinese banking industry, two outputs are used, which are interest income and non-interest income. Both the interest income and non-interest income make up the total income for banks. This output was used by Ouenniche and Carrales (2018) in estimating efficiency in the UK banking industry. There are three inputs considered in the current study: number of employees, fixed assets and deposit. The use of number of employees and fixed assets as inputs is in accordance with Fukuyama and Weber (2017), while the use of deposits as input is in line with the argument of Yildirim (2002). The related three input prices are price of labour, price of capital and price of funds, the measurements of which are the ratio of personal expenses to the number of employees (Dong et al., 2016), the ratio of non-interest expenses to fixed assets (Tan \& Floros, 2018) and the ratio of

\footnotetext{
1 We collect the sample data from Fitch connect as well as banks' annual financial statements. Originally data of 100 Chinese banks was collected. We remove the ones with missing observations of certain variables we use in our analysis and we also remove the banks with missing data for specific year(s). Totally we clean the data and form the balance dataset of 72 banks in China over the period 2007-2017 without any missing values of variables and years.
} 
Table 2 Testing hypothesis on returns to scale: CRS versus VRS

\begin{tabular}{llll}
\hline Year & $S$-statistic & Critical value & $p$ value \\
\hline 2007 & 0.8161 & 0.6885 & 0.38 \\
2008 & 0.7945 & 0.6776 & 0.245 \\
2009 & 0.7988 & 0.6876 & 0.215 \\
2010 & 0.7669 & 0.7083 & 0.115 \\
2011 & 0.7458 & 0.655 & 0.195 \\
2012 & 0.7681 & 0.6208 & 0.285 \\
2013 & 0.7494 & 0.7008 & 0.135 \\
2014 & 0.8066 & 0.7225 & 0.205 \\
2015 & 0.7994 & 0.6783 & 0.275 \\
2016 & 0.8002 & 0.5647 & 0.305 \\
2017 & 0.8009 & 0.7403 & 0.15 \\
\hline The & hypotheses & of & the \\
$H_{0}:$ & Technology exhibits constant returns to scale. \\
$H_{1}:$ & Technology exhibits variable returns to scale.
\end{tabular}

interest expenses to total deposits (Tan, 2016). Table 1 shows the summary statistics of the variables used in the efficiency estimation. The table shows that Chinese commercial banks have a bigger difference in total deposits, while the difference in the number of employees among Chinese commercial banks is relatively small. Regarding the input prices among Chinese commercial banks, it is found that Chinese commercial banks have a smaller difference in the price of capital, while the differences in the price of labour and price of funds are bigger. However, the difference between these two input prices is not big, with standard deviation of price of labour 73 and the one of price of funds 62 .

\subsection{Preliminary analysis of DEA scores: constant versus variable returns to scale}

In this study we have adopted the representations of constant returns to scale technology, Eq. (16), because we tested the null hypothesis that the constant returns to scale and the variable returns to scale are the same. For the construction of variable returns to scale technology, all we need to do is to append $\sum_{j} \lambda_{j}=1$ to Eq. (16).

The bootstrapped S-statistic is estimated based on the scale efficiency, i.e., the ratio of the VRS and the CRS output distance functions (Bogetoft \& Otto, 2011). The null hypothesis is that the technology exhibits constant returns to scale globally. The alternative hypothesis is that the technology exhibits variable returns to scale. Table 2 shows that we cannot reject the null hypothesis. Since the hypothesis of global constant returns to scale is not rejected statistically, we employ the constant returns to scale specification in our empirical analysis. For this testing, we utilized the R codes developed by Bogetoft and Otto (2011).

Before concluding this sub-section, we have a remark on the standard input-oriented allocative efficiency measure (15) and the indirect allocative efficiency (11) in relevance to our dataset. Our dataset supports the constant returns to scale specification, and hence we have the following results:

(i) $\quad I T E \equiv D_{O}(x, y)=1 / D_{I}(x, y) \equiv \operatorname{inpTE}$. 
(ii) $I D_{O}(w / c, y)=C(y, w / c)$.

Particularly, the relationships (i) and (ii) hold for $(x, y) \in T$ (equivalently, $y \in P(x)$ ) as in our dataset with positive input-output variables. Under the assumption of constant returns to scale, the nonparametric input distance function is constructed as

$$
\frac{1}{D_{I}(x, y)}=\min _{\theta, \lambda}\left\{\theta \mid \begin{array}{l}
\sum_{j=1}^{J} x_{n j} \lambda_{j} \leq \theta x_{n}, \quad n=1, \ldots, N ; \quad \sum_{j=1}^{J} y_{m j} \lambda_{j} \geq y_{m}, \quad m=1, \ldots, M ; \\
\lambda_{j} \geq 0, \quad j=1, \ldots, J ; \quad 0<\theta \leq 1
\end{array}\right\}
$$

Note that the optimal values of $\varphi$ and $\theta$ in the definitions of the output distance function $(8,18)$ and the input distance function $(20)$, respectively, as long as $(x, y) \in T$. As a consequence, we can establish:

$$
\begin{aligned}
D_{O}(x, y) & =\max _{\varphi, \lambda}\left\{\varphi \mid \begin{array}{l}
\sum_{j=1}^{J} x_{n j} \lambda_{j} \leq x_{n}, \quad n=1, \ldots, N ; \quad \sum_{j=1}^{J} y_{m j} \lambda_{j} \geq \varphi y_{m}, \quad m=1, \ldots, M ; \\
\lambda_{j} \geq 0, \quad j=1, \ldots, J ; \quad \varphi \geq 1
\end{array}\right\} \\
& =\frac{\min _{\theta, \lambda^{\prime}}\left\{\theta \mid \begin{array}{l}
\sum_{j=1}^{J} x_{n j} \lambda_{j}^{\prime} \leq \theta x_{n}, \quad n=1, \ldots, N ; \quad \sum_{j=1}^{J} y_{m j} \lambda_{j}^{\prime} \geq y_{m}, \quad m=1, \ldots, M ; \\
\lambda_{j}^{\prime} \geq 0, \quad j=1, \ldots, J ; \quad 0<\theta \leq 1
\end{array}\right\}}{}=\frac{1}{D_{I}(x, y)}
\end{aligned}
$$

where $\lambda_{j}^{\prime}=\lambda_{j} / \varphi, j=1, \ldots, J$ and $\theta=1 / \varphi$. Also, we can establish the following equivalence: 


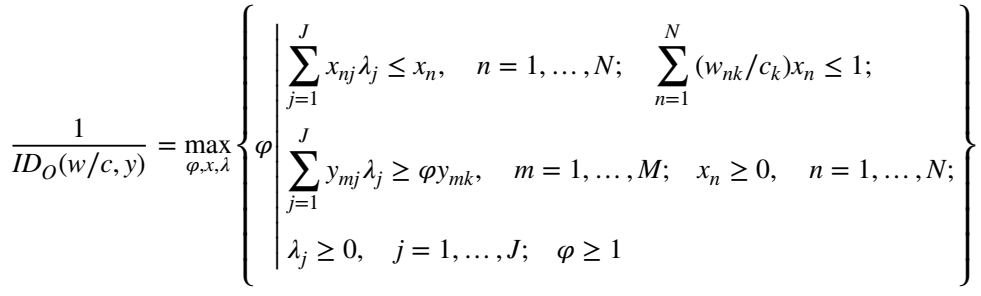

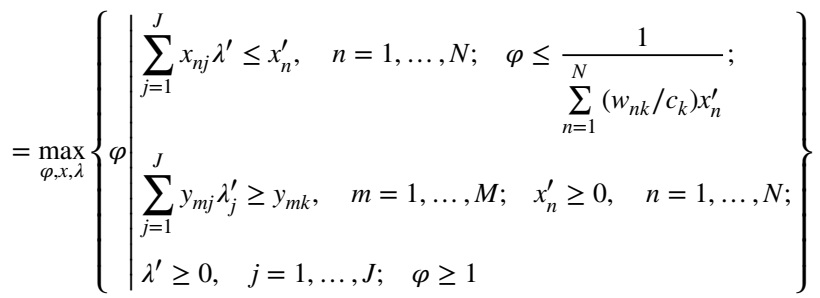

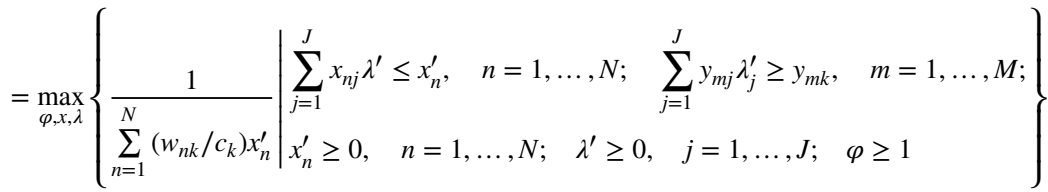

$$
\begin{aligned}
& =\min _{x^{\prime}, \lambda} \frac{1}{\left\{\sum_{n=1}^{N}\left(w_{n k} / c_{k}\right) x_{n}^{\prime} \mid \begin{array}{l}
\sum_{j=1}^{J} x_{n j} \lambda^{\prime} \leq x_{n}^{\prime}, \quad n=1, \ldots, N ; \quad \sum_{j=1}^{J} y_{m j} \lambda_{j}^{\prime} \geq y_{m k}, \quad m=1, \ldots, M ; \\
x_{n}^{\prime} \geq 0, \quad n=1, \ldots, N ; \quad \lambda^{\prime} \geq 0, \quad j=1, \ldots, J ; \quad \varphi \geq 1
\end{array}\right\}} \\
& =\frac{1}{C(y, w / c)}
\end{aligned}
$$

where $x_{n}^{\prime}=x_{n} / \varphi$ and $\lambda_{j}^{\prime}=\lambda_{j} / \varphi$. This indicates $I D_{O}(w / c, y)=C(y, w / c)$ for $(x, y) \in T$. Färe and Primont (1995) showed the results (i) and (ii) for a general production theoretic framework on pages 24 and 83, respectively. The nonparametric results (i) and (ii) indicate that, under constant returns to scale, we have:

$$
I A E=\frac{I D_{O}(w / c, y)}{D_{O}(x, y)}=C(y, w / c) D_{I}(x, y)=\frac{C(y, w)}{w x} D_{I}(x, y)=s t d A E .
$$

where $c=w x$. Therefore, in our case $I A E$ is equivalent to $s t d A E$. It should be noted that the equivalence between $I A E$ and $s t d A E$ does not hold in general.

\subsection{Stability analysis based on full-dimensional and non-full-dimensional faces}

Under the constant returns to scale, the dual form of the production possibility set can be constructed by

$$
\left\{(x, y) \mid \text { for all }(v, u) \in \mathfrak{R}_{+}^{N} \times \mathfrak{R}_{+}^{M} \text {, there is } k \in \partial(T) \text { with }-v x+u y \leq-v x_{k}+u y_{k}\right\}
$$


Table 3 Strongly efficient banks and MEFs (maximal efficient faces)

\begin{tabular}{llll}
\hline Year & $\begin{array}{l}\text { No. of strong } \\
\text { efficient banks }\end{array}$ & No. of MEFs & $\begin{array}{l}\text { No. of non-full } \\
\text { dimensional } \\
\text { MEFs }\end{array}$ \\
\hline 2007 & 11 & 10 & 2 \\
2008 & 11 & 12 & 3 \\
2009 & 12 & 9 & 2 \\
2010 & 10 & 7 & 1 \\
2011 & 9 & 6 & 2 \\
2012 & 9 & 6 & 2 \\
2013 & 10 & 8 & 2 \\
2014 & 9 & 7 & 2 \\
2015 & 7 & 6 & 1 \\
2016 & 8 & 5 & 3 \\
2017 & 12 & 14 & 1 \\
\hline
\end{tabular}

The acronym MEF stands for maximal efficient face and the collection of all maximal efficient faces is the production frontier

where $\partial(T)=\left\{k \mid\left(x_{k}, y_{k}\right)\right.$ is a vertex of $\left.T\right\}$ is an index set of extreme points (vertices) of T. For Eq. (23), see for example Briec and Leleu (2003), Briec and Kerstens (2003) and Olesen and Petersen (2015).

Now we consider faces and facets under constant returns to scale. A set $F \subseteq T$ is said to be a face if there exists some $(v, u) \in \mathfrak{R}_{+}^{N} \times \mathfrak{R}_{+}^{M}$ satisfying Eq. (23) such that $v x-w y=0$ for all $(x, y) \in F$. Let $\operatorname{Eff}(T)=\left\{(x, y) \in T \mid(x,-y) \geq\left(x^{\prime},-y^{\prime}\right)\right.$ and $(x,-y) \neq\left(x^{\prime},-y^{\prime}\right) \Rightarrow$ $\left.\left(x^{\prime}, y^{\prime}\right) \notin T\right\}$ be a strongly efficient frontier of T. A face $F \subseteq E f f(T)$, which is an efficient face, is said to be a maximal efficient face (MEF) if there exists no efficient face $G$ such that $G \supseteq F$ and $G \neq F$. Note that the collection of all MEFs is $E f f(T)$. Decomposing the efficient frontier into a finite number of MEFs, Fukuyama and Sekitani (2012) emphasized that the MEFs are often non-full dimensional. A facet is full-dimensional but a face is either full-dimensional or non-full-dimensional. The existence of non-full-dimensional faces $^{2}$ in DEA was discussed by Olesen and Petersen $(1996,2003)$.

Consider the input-output data matrix $\hat{D}_{h}$ consisting of some DMUs in the index set $\hat{J}_{h}=\left\{k \in F_{h} \mid-\hat{v} x_{k}+\hat{u} y_{k}=0\right\}$, where $h$ is the $h$-th face. The matrix dimension of $\hat{D}_{h}$ is $(N+M) \times\left|\hat{J}_{h}\right|$ where $\left|\hat{J}_{h}\right|$ represents the number of elements in the index set of $\hat{J}_{h}$. Let $\operatorname{rank}\left(\hat{D}_{h}\right)$ denote the rank of $\hat{D}_{h}$. If $\operatorname{rank}\left(D_{h}\right)=N+M-1=\left|F_{h}\right|$, then the face $F_{h}$ is fulldimensional. In our case we employ a constant returns to scale so we refer to the members of a face as "forerunners" 3 ". If a face is non-full-dimensional, then rates of substitution are not well-defined over the face, as mentioned above. In contrast, if a full-dimensional face or facet exists, rates of substitution are well defined over the facet. Therefore, we perceive a non-full dimensional face as being an unstable one.

An efficient DMU that is located on a non-full-dimensional face but not on a full-dimensional facet, may be thought of as being a lack of competition because a

\footnotetext{
2 A non-full dimensional face is called ill-conditioned by Olesen and Petersen (1996).

3 Tone (2010) called them "friends" by confining himself to a full-dimensional facet case.
} 
Table 4 Enumeration of maximal efficient faces (MEFs)

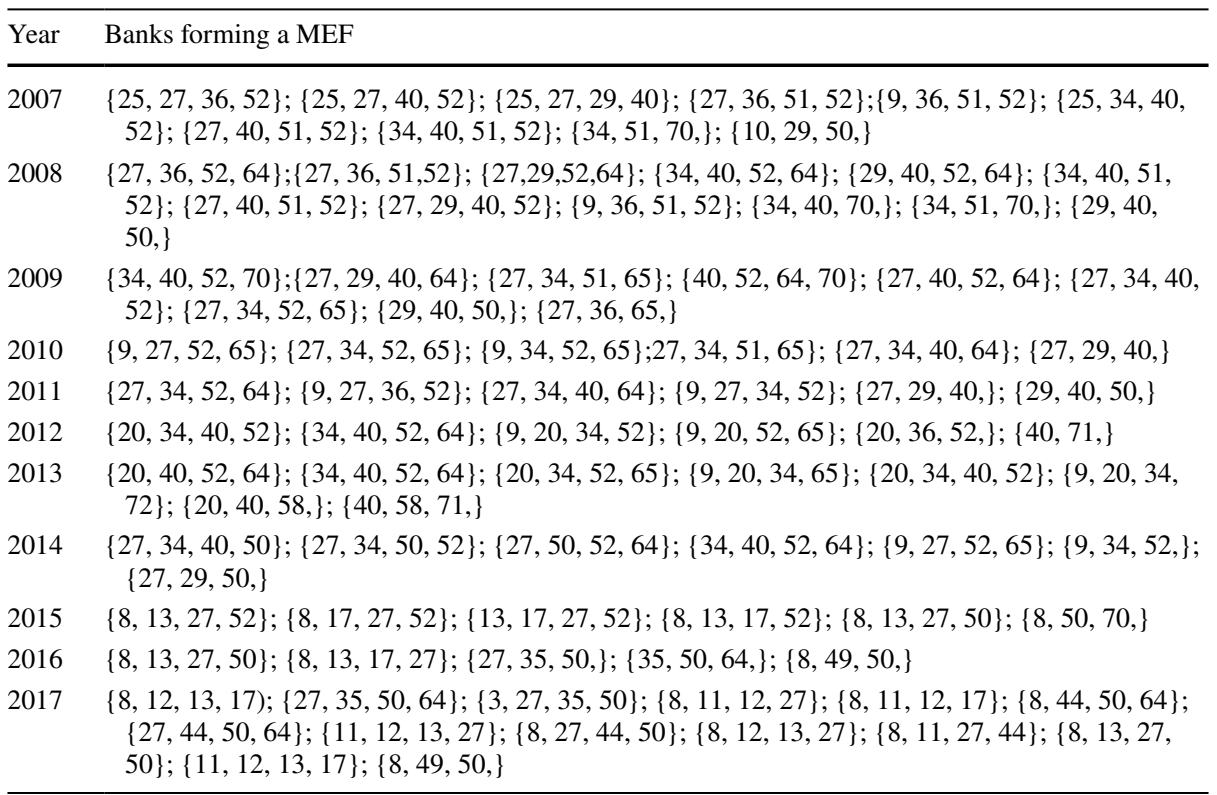

Each entry of $\{\ldots\}$ shows a bank's ID, which forms a maximal efficient face. For example, the numbers of $\{25,27,36,52\}$ for year 2007 indicate that the banks numbered $25,27,36$ and 52 form the maximal efficient face of $\{25,27,36,52\}$

non-full-dimensional efficient face is spanned only by less than $\mathrm{N}+\mathrm{M}-1$ DMUs. This is so because a face based on constant returns to scale contains the origin of inputs and outputs.

Table 3 displays the numbers of strongly efficient banks, strongly efficient faces (i.e., MEFs) and non-full dimensional MEFs. ${ }^{4}$ The strongly efficient frontier constitutes both full dimensional and non-full dimensional MEFs. The number of strongly efficient banks varies from year to year, with a significant difference in number from seven in 2015 to twelve in 2017. The table also shows that there exists at least one non-full dimensional MEFs for all sample years (see Olesen and Petersen (1996) and Briec and Leleu (2003) on this point). The number of full dimensional MEFs ranges from two (=5-3) in 2016 to thirteen $(=14-1)$ in 2017 . Therefore, there appears to be an indication of instability of China's financial technology (or this can be thought of as its dynamism).

The interpretation of instability can also be supported by the fact that no bank is efficient for all sample years and some banks forming non-full dimensional MEFs do not contribute to any full dimensional MEFs. Regarding the latter case, there are one to three such banks for each sample year. For example, banks \#10, \#50 and \#70 in 2007 do not have any frontrunner friends except for the banks on the same non-full dimensional MEFs. See

\footnotetext{
${ }^{4}$ Olesen and Petersen (1996) suggested using Qhull for estimating strongly efficient faces.
} 
Table 5 descriptive statistics of corporate social responsibility indicators and controlled variables

\begin{tabular}{llllll}
\hline Variables & Observations & Means & Standard deviation & Minimum & Maximum \\
\hline Donations & 792 & $1,327,559$ & $1,911,555$ & 10,091 & $9,932,249$ \\
Balance of green credit & 792 & $3,221,967$ & $4,732,667$ & 12,694 & $4.19 \mathrm{e}+07$ \\
Ratio of green credit in total loans & 792 & 0.08 & 1.88 & 0.01 & 0.29 \\
Loans to SMEs & 792 & $1.51 \mathrm{e}+07$ & $2.40 \mathrm{e}+07$ & 118,417 & $1.52 \mathrm{e}+08$ \\
Ratio of loans to SMEs in total & 792 & 0.11 & 1.68 & 0.01 & 0.25 \\
$\quad$ loans & 792 & 17.61 & 2.048964 & 11.42 & 22.11 \\
Bank size & 792 & 0.857 & 2.01 & 0.01 & 21.84 \\
Bank liquidity & 792 & 0.146 & 0.173 & 0.019 & 1.17 \\
Bank capital & 792 & 0.156 & 1.08 & 0.0001 & 12.53 \\
Bank risk & & & & &
\end{tabular}

In the second-phased regression analysis, we investigate the impact of corporate social responsibility indicators including donations, Balance of green credit and loans to Small and Medium-sized enterprises (SMEs). In addition, we control for a number of bank specific variables including bank size, measured by the natural logarithm of total assets, bank liquidity, measured by the ratio of liquid assets to total assets, bank capital measured by the ratio of equity capital to total assets, and bank risk measured by the ratio of loan loss provision to total loans. Donations, balance of green credit and loans to SMEs are in RMB 10,000, all the other indicators are in ratios

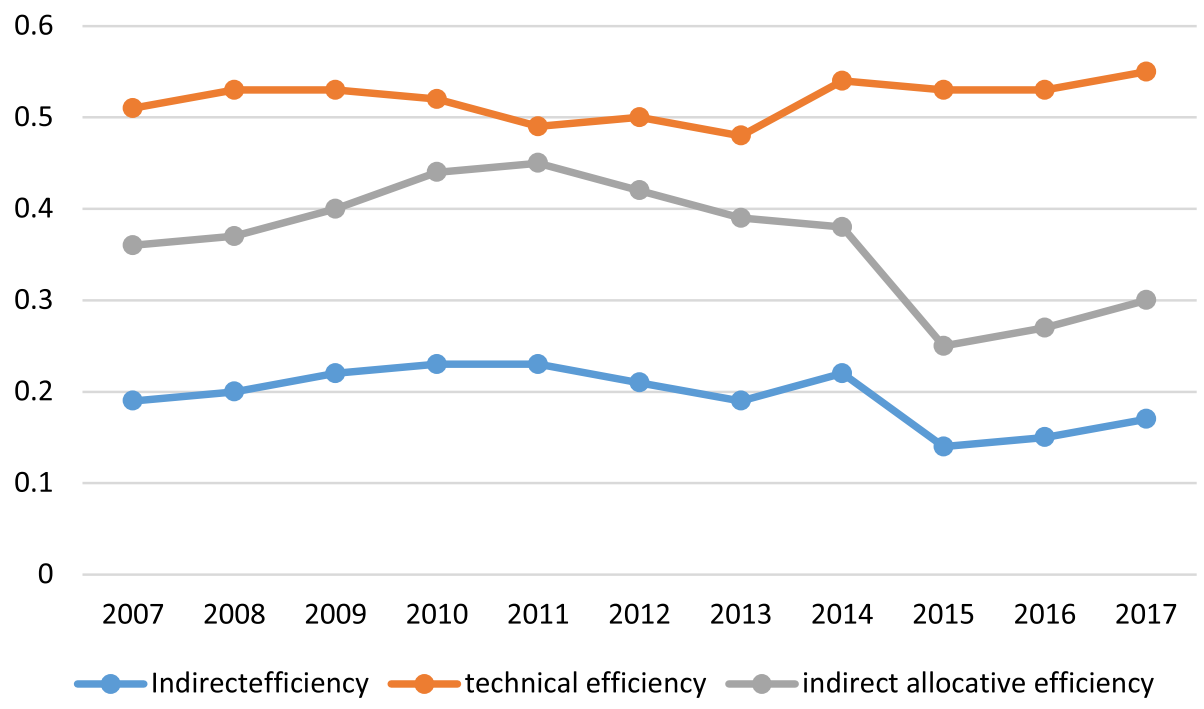

Fig. 2 Indirect efficiency, technical efficiency and indirectly allocative efficiency in the Chinese banking industry. Note: the blue line represents the level of indirect technical efficiency, the grey line stands for the level of indirect allocative efficiency and the orange line is the level of technical efficiency. The relationship between these three can be expressed as indirect technical efficiency $=$ technical efficiency* indirect allocative efficiency 
Table 6 observed and targeted amounts of Labour in the Chinese banking industry

\begin{tabular}{llll}
\hline & Observed amount & Target amount & Percentage change \\
\hline 2007 & 32,250 & 944,400 & 28.28372093 \\
2008 & 32,876 & 712,874 & 20.68372065 \\
2009 & 33,543 & 813,357 & 23.24818889 \\
2010 & 34,395 & 699,062 & 19.32452391 \\
2011 & 34,680 & 712,874 & 19.55576701 \\
2012 & 36,848 & 867,417 & 22.54040925 \\
2013 & 38,818 & $1,178,195$ & 29.3517698 \\
2014 & 39,529 & $1,174,097$ & 28.70216803 \\
2015 & 40,015 & 814,825 & 19.36298888 \\
2016 & 39,936 & 780,828 & 18.55198317 \\
2017 & 41,743 & 663,962 & 14.9059483 \\
\hline
\end{tabular}

The observed amount is the number of actual employees for the sample and it is calculated by taking an average of all the banks in a specific year. Because we consider that the potential increase in the number of employees would be another aspect of banks' corporate social responsibility from the perspective of reducing the unemployment of the economy. Therefore, we estimate the level of "target amount" of employees to see whether banks could contribute to society from this perspective. If the target amount is more than the actual observed amount, that indicates banks should increase the number of employees, through which not only efficiency can be improved, but also banks could make contributions to society from this corporate social responsibility. Percentage change (last column) is calculated by using the target amount minus the observed amount and then use the proceed to divide by the observed amount. A larger percentage indicates that there is a larger potential in increasing the employment

Table 4 that enumerates all MEFs consisting of full and non-full dimensional ones for each year. $^{5}$

\subsection{Variables for the second stage regression analysis}

In the second stage regression analysis, we investigate the impact of CSR on bank efficiency by using three specific corporate social responsibility indicators, namely donations, balance of green credits and loans to SMEs. We use these three specific indicators rather than the general index or ethical parameters used by previous empirical studies. This arguably significantly contributes to the empirical literature. In order to check the robustness of the results, the current paper tests four different models. The first model only considers the impact of donation on bank efficiency, while model 2 investigates purely the impact of balance of green credits on bank efficiency. The third model examines the influence of loans to SMEs on bank efficiency, and model 4 evaluates the joint impacts of these three indicators on bank efficiency. We use four controlled variables in all these four different

\footnotetext{
5 Table 4 give all MEFs. For example, the first MEF in 2007 is represented by $F_{1}$ that comprises banks 25 , 27, 36 and 52 and the tenth MEF in the same year is $F_{10}$ consisting of banks 10,29 and 50. Note that $F_{1}$ and $F_{10}$ are full and non-full dimensional MEFs, respectively.
} 
models, including bank size, measured by the natural logarithm of total assets (Tan \& Floros, 2013); bank liquidity, measured by the ratio of liquid assets to total assets (Hassan \& Marton, 2003); bank capitalization, measured by the ratio of equity capital to total assets (Kwan \& Eisenbeis, 1997); and bank risk, measured by the ratio of loan loss provision to total loans (Chortareas et al., 2011). Table 5 shows the statistics of these three CSR indicators and the controlled variables. The table shows that among these three different CSR indicators, Chinese commercial banks have a bigger difference in the volumes of loans granted to SMEs, while the difference in the volumes of donations is smaller than the one for balance of green credits. Regarding the controlled variables, it is suggested that the difference in the capital level is the smallest. This is mainly attributed to the capital regulation in the Chinese banking industry, while, although there is a bigger difference in the level of credit risk undertaken by the Chinese commercial banks, it is still smaller than the level of liquidity and bank size.

\section{Results}

It is suggested from Fig. 2 that overall; the indirect allocative efficiency is lower than technical efficiency over the examined period. It indicates that Chinese banks have relatively higher ability to minimize the cost in order to maximize the output production than the ability to manage a variety of inputs to produce a mix of outputs, while higher technical efficiency than allocative efficiency suggests that the former contributes more than the latter to the overall efficiency in the Chinese banking industry. In other words, the main source of inefficiency in the Chinese banking industry is derived from the allocative inefficiency. Therefore, Chinese commercial banks should focus more on improving the ability to manage input investment in the production process.

In terms of one input, the number of employees, we notice from Table 6, kept increasing in the Chinese banking industry over the examined period (except there is a slight decrease in 2016 compared to the previous year). We analyse whether there is a possibility to increase the number of employees, as reflected by the "target amount" in the table. ${ }^{6}$ The target amount estimated is the number of employees that can be recruited for each of the years that will have a favourable effect on bank efficiency in China. If, comparing to the observed amount, the target amount is bigger, this represents that the Chinese banking industry could employ more people, through which banking sector efficiency can be improved and corporate social behaviour can be engaged in by the Chinese commercial banks to reduce the unemployment level for the economy. ${ }^{7}$ We can see from the table that over the examined period, there is a possibility for the Chinese banking industry to increase the number of employees with the largest supposed increase in 2013, which is nearly $30 \%$. The percentage change is calculated as the difference between the target amount and the

\footnotetext{
6 The target amount is obtained from the optimal solution $x_{1}^{*}$ in Eq. (14).

7 We collect the data from the world bank database for the number of labour force and unemployment rate over the period 2007-2017 from which we calculate the volume of unemployment. From table 6, we calculate the additional employment that can be accommodated in the banking industry over the same period and finally, we calculate the new unemployment rate, considering that additional employment can be accommodated in the banking industry. The results show that over the period, the banking sector at least can contribute to reduce the unemployment rate by $0.8 \%$ in 2017 , while in 2013 , they can contribute the most by reducing the unemployment rate by $1.46 \%$. For all the other years, the percentage of reduction in the unemployment rate is between $0.8 \%$ and $1.46 \%$.
} 


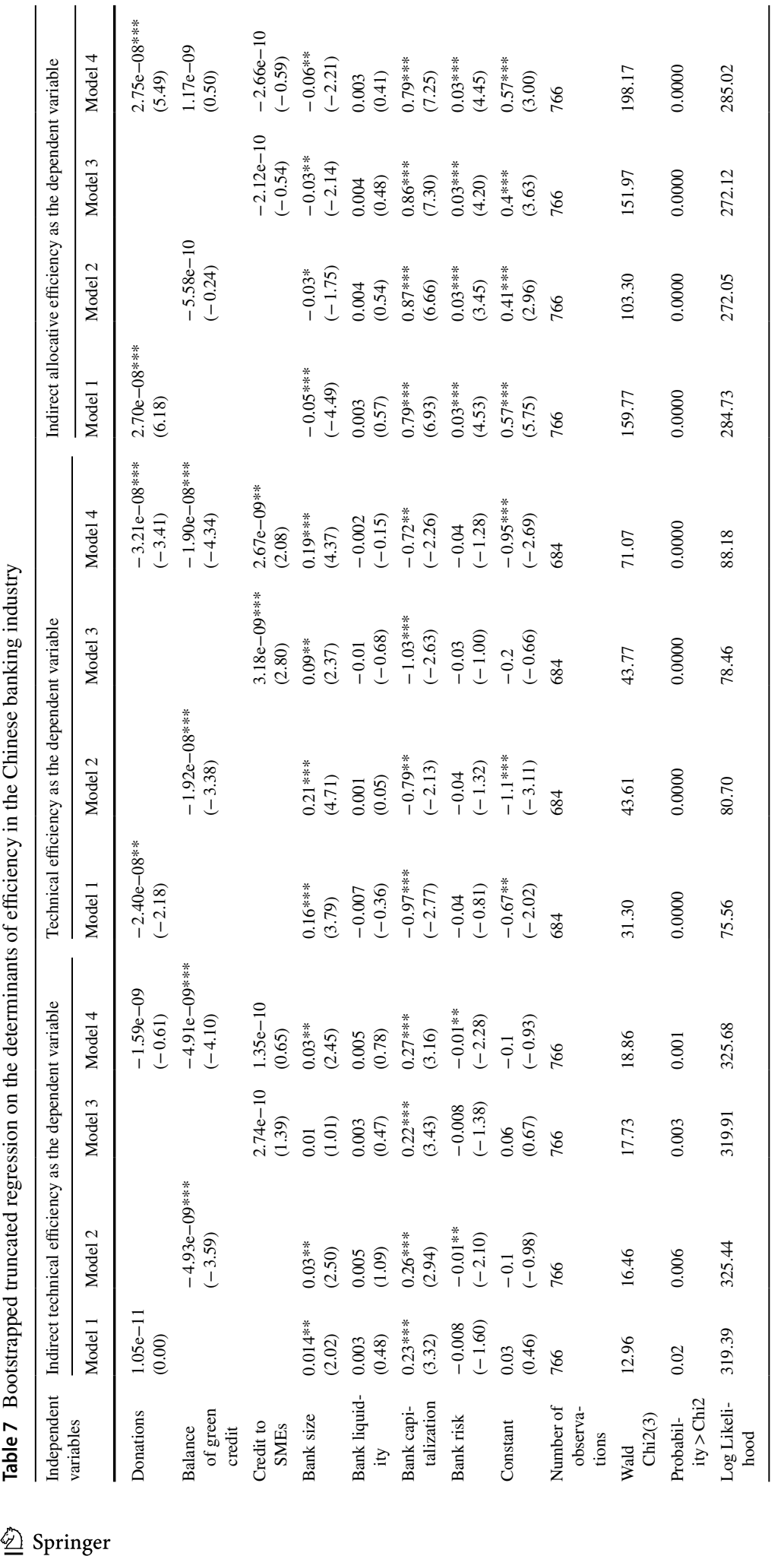




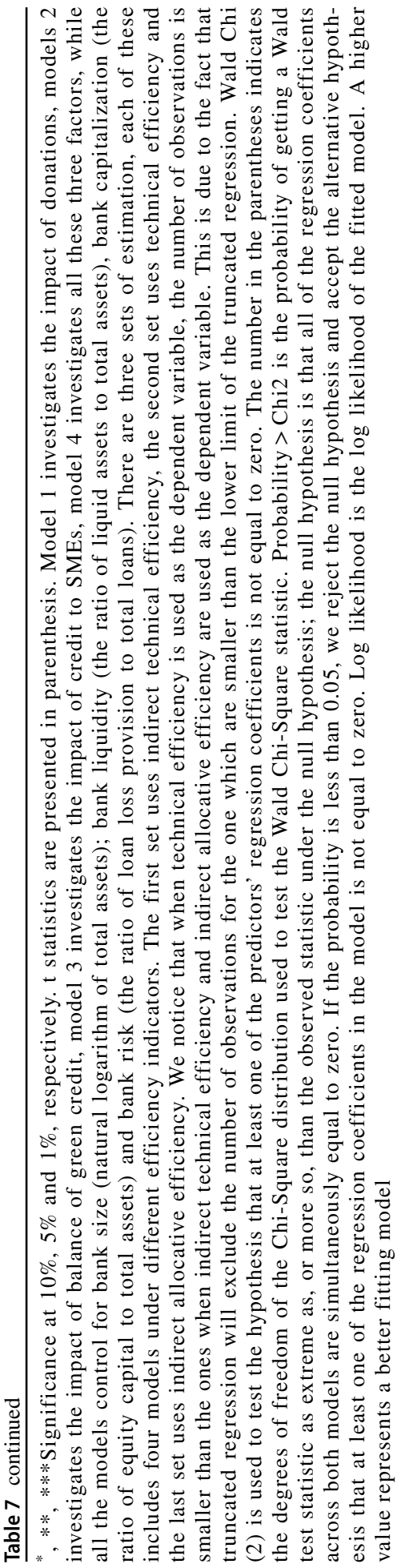




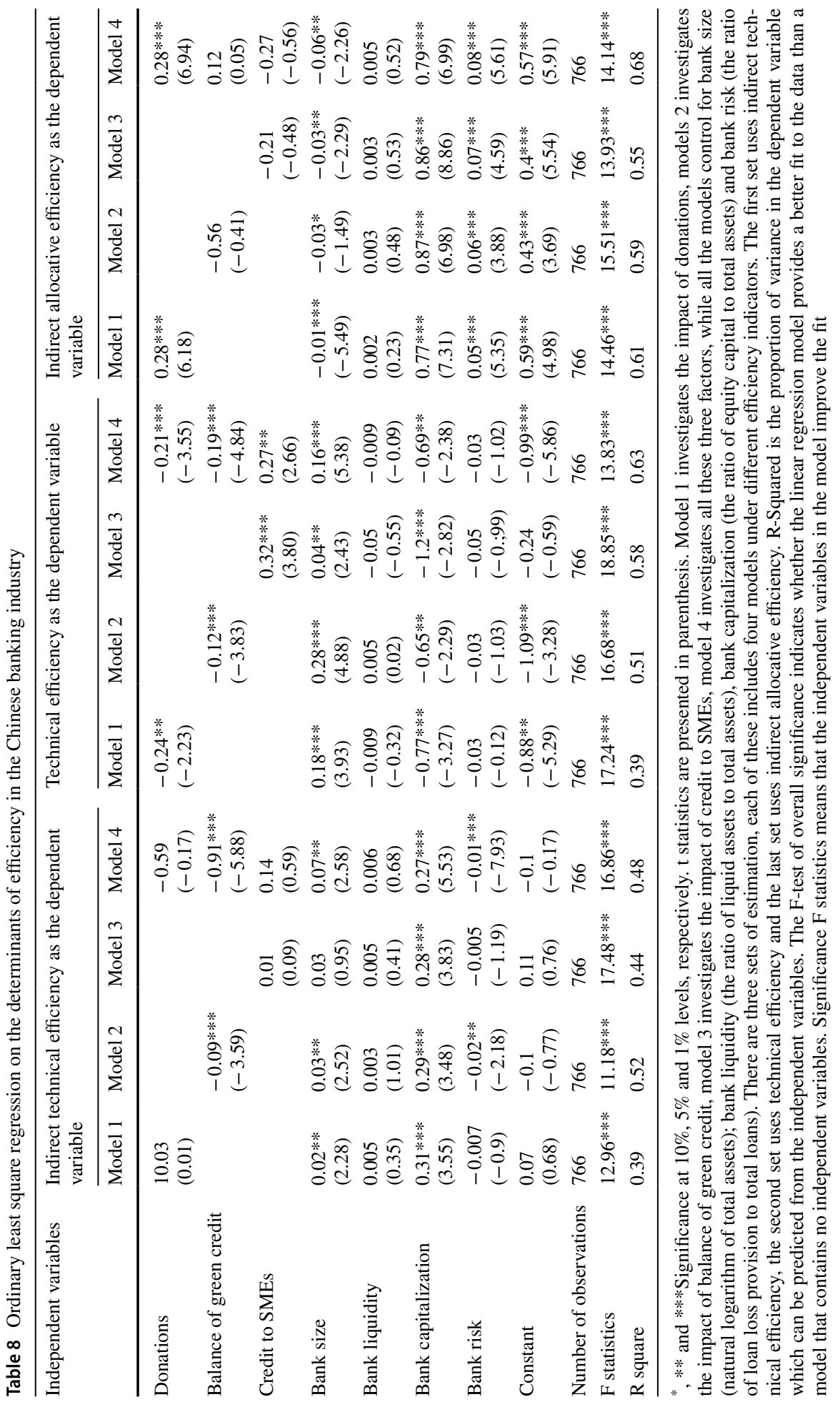


observed amount, then use the proceed to divide by the observed amount. The larger the results, the bigger the scale of increase in the number of employees can be engaged in by the Chinese commercial banks. This result indicates that it is possible for Chinese banks to engage in this corporate social behaviour to alleviate the unemployment problem for society through employing more people.

In the second stage, we analyze the determinants of efficiency in the Chinese banking industry with a special focus on the impacts of donations, balance of green credits and loans to SMEs on bank efficiency, the results of which are reported in Table 7. With regard to the econometric technique used to examine the impact of CSR on bank efficiency, we use Simar and Wilson (2007) Bootstrapped truncated regression analysis. The results show that balance of green credits is significantly and negatively related to indirect technical efficiency, indicating that higher volumes of green credits made by Chinese commercial banks decrease their efficiency level. It is shown that loans to SMEs and donations are not significantly related to bank efficiency, as reflected in model 3 and model 4 . When investigating the impacts of CSR on technical efficiency and indirect allocative efficiency, the findings suggest that balance of green credits is significantly and positively related to the level of technical efficiency, indicating the Chinese commercial banks granting more credits to the green activities have higher levels of efficiency. In addition, the findings show that loans to SMEs have a significant and positive impact on technical efficiency, indicating that the technical efficiency of Chinese banks can be improved by providing more loans to SMEs. This can be explained by the fact that larger volumes of loans to SMEs can not only save banks' costs derived from economies of scale, but also the banks will benefit from the cost savings from economies of scope. Finally, it is reported that higher levels of donations reduce the level of technical efficiency but increase the level of indirect allocative efficiency.

\section{Additional robustness check}

We have conducted the robustness check by two ways. First, The Simar and Wilson bootstrapped truncated regression adopted in the current study has the advantage of being able to produce valid estimates for the parameters in the regression model (Tan, 2016). However, the second-stage regression analysis can generate robust results using the Ordinary Least square estimator (OLS) when the Data envelopment analysis is used in the first stage to estimate the efficiency level (Estelle et al. 2010; Mcdonald, 2009). Therefore, in order to check the robustness of the results, we engage in additional econometric test in the second stage under the Ordinary least square estimator, the results of which are reported in Table 8 . Finally, due to the consideration that there would be potential endogeneity problems in the analysis, i.e. there may be a two-way causality or an omitted variable that determines the relationship between the CSR and the efficiency, we use two-stage least square instrumental variable technique to check the accuracy and robustness of our results. We follow Adeabah and Andoh (2020) to include tangibility measured by the natural logarithm of fixed assets as the instrument. The validity of the instrument is tested through the Wooldridge's over-identifying test. We also conduct two different tests for the potential endogeneity of the variables: (1) Wooldridge's robust score test; (2) robust regression exogeneity test. The null hypothesis is the variables are exogenous for both of the two tests. The results of the two-stage least square instrumental variable regression technique are reported in Table 9. As we can see from the results of these two tables, compared to the original 


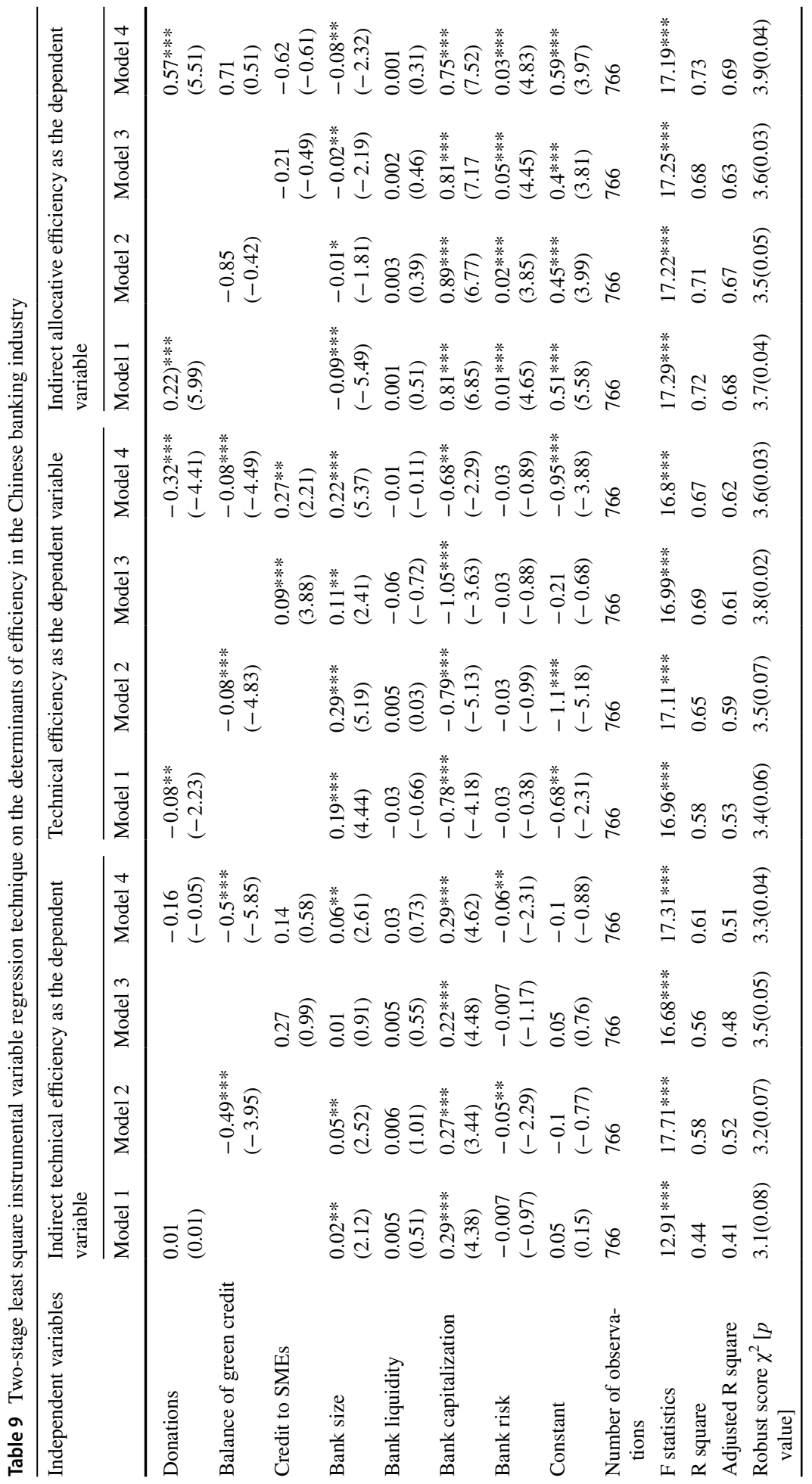




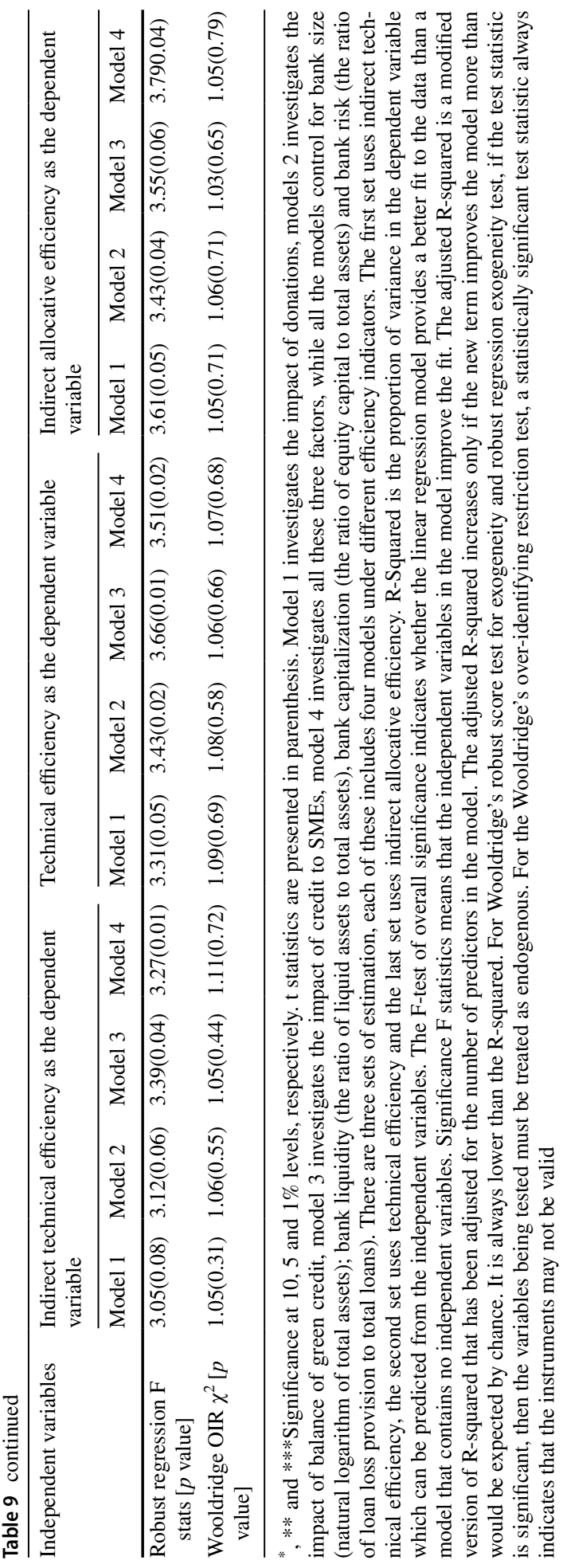


estimation reported by the Bootstrapped truncated regression in Table 7, we have quantitatively similar results. In particular, we confirm that balance of green credit has a significant and negative impact on indirect technical efficiency, while the effect is significant and positive for technical efficiency. The impact of loans to small and medium sized enterprises on bank efficiency is significant and positive. Finally, all the tables report that technical efficiency is significantly and negatively affected by donations, while indirect allocative efficiency is positively affected. In summary, our original estimation is accurate and robust.

\section{Discussion}

As far as we are concerned, the current paper is the first piece of research attempting to investigate the "indirect allocative efficiency" in the Chinese banking industry, which significantly contributes to the empirical literature in the Chinese banking efficiency from a methodological perspective. Our results regarding the fact that Chinese commercial banks have higher level of technical efficiency compared to allocative efficiency is in line with Chen et al. (2015). In addition, although number of employees has been used as one important input in the production process to measure efficiency in the Chinese banking industry (Ariff \& Can, 2008; Asmild \& Matthews, 2012), the potential increase in the number of employees has not been considered as an important indicator from CSR perspective. The current paper significantly contributes to the banking and CSR studies by being the first study to propose the potential increase in the number of employees as one aspect of CSR and to apply this concept to the Chinese banking study. This is supposed to not only fill in a gap in the empirical literature, but also to generate very interesting and important policy implications. Our results show that there is a possibility to further increase the number of employees in the Chinese banking industry. This finding is in accordance with the corporate social performance theory, the main argument of which is to encourage corporations to engage in relevant activities that will provide benefits to the society. The possibility of potential increase in the number of employees will provide benefits to the society from the perspective of employment improvement and poverty reduction.

Our results, compared to Ciciretti et al. (2014), provide more important, more specific and more concrete policy implications to the Chinese banking industry. We argue that an increase in the volume of donations will further lead to an improvement in the level of indirect allocative efficiency of Chinese commercial banks. This means that Chinese commercial banks can increase their level of outputs without any increase in their costs if they provide more donations to the society. This is in line with the corporate social performance theory and stakeholder theory. An increase in the volume of donations is supposed to have a significant and positive impact on the development of society or promote equal economic development between different geographical areas in China. For instance, donations to different universities for their research and scholarship are supposed to increase the volumes and improve the quality of their research activities. This will further increase the possibility for the Chinese universities to generate influential research outputs, from which different parties in society, including people, companies and government can get benefits. Furthermore, donations to the poorer areas in China (western part of China) will further improve their infrastructure construction and have a significant and positive impact on their economic development. This will further reduce the gap (economic development imbalance) between the eastern part of China and western part of China. We further argue that Chinese commercial banks should reduce the volume of green credits in order to improve 
the overall indirect technical efficiency. In comparison, although Ciciretti et al. (2014) find that community responsibility has a significant and positive impact on efficiency, it is very hard to generate specific and accurate policy implications. As discussed previously in the literature review, Zhu et al. (2017) use social contribution value per share to measure corporate social responsibility; it is impossible for the results to be useful for the banks which are not listed, whereas, the variables we proposed are applicable to all banks. Reduction in the volume of green credits granted by the Chinese commercial banks is mainly in line with the shareholder theory, the main argument of which is that the corporations should engage in these activities with the sole purpose of maximizing the shareholders' value. Because our findings show that reduction in the volume of green credits will lead to an improvement in the overall indirect technical efficiency, Chinese commercial banks should better allocate the resources in the production process and further create value for their shareholders through decreasing the volumes of credits granted to environmentally friendly companies and projects. However, this is not good for the society, due to the fact that the behaviour has the possibility of creating pollution in society. Therefore, we argue that there would be a possible conflict between corporate social performance theory, stakeholder theory and shareholder theory.

\section{Summary, conclusion and policy implications}

The current study contributes to the banking literature in general by innovatively developing a gain function based on direct and indirect distance functions to measure the efficiency level in the Chinese banking industry. We use the number of employees as one input in the efficiency analysis, while at the same time, we propose the potential increase in the number of employees as a CSR indicator. In addition, this work is the first piece of study investigating CSR in the banking sector by using three specific indicators, namely donations, balance of green credits and loans to SMEs. The financial crisis of 2007-2009 caused the government and regulatory authorities to attach great importance to the stability of the banking industry. The current study fills in the gap in the empirical literature by being the first piece of research investigating the impact of these specific CSR activities on the risk levels in the banking context under a fixed effect estimation.

The results of the current study show that the potential gains obtained from the improvement in technical output-efficiency are more than the ones attained from the improvement in allocative output-efficiency through reallocating the input resources, and that the Chinese banking industry can enhance its CSR activity from the perspective of increasing the number of employees. The findings from the second stage Bootstrapped truncated regression show that: (1) balance of green credits is significantly and negatively related to indirect technical efficiency, but positively related to technical efficiency; (2) there is a significant and positive relationship between loans to SMEs and technical efficiency; (3) donations are found to be significantly and negatively related to technical efficiency, but positively related to indirect allocative efficiency.

The results from the current study provides new and interesting policy implications. (1) Chinese commercial banks can increase the number of their employees. This specific policy is our significant contribution to the empirical efficiency and CSR literature and most importantly, it is a very original contribution. It has important policy implications for the government, because this policy can benefit the economy from four different perspectives; 
firstly, increase in recruitment is a CSR behaviour, which is good for bank image and reputation; second, increase in recruitment will reduce poverty; third, increase in the number of employees will have the possibility to increase bank efficiency; lastly, increase in the number of employees will contribute to the economy by reducing the unemployment rate.

(2) Relevant regulations should be formulated to encourage bank donations and reduce the volumes of green credits granted by the Chinese commercial banks. Present policy does not encourage the Chinese banks to engage in CSR in terms of protecting the environment. Additional policies should be made requiring other financial and non-financial institutions to provide credits to environmentally friendly companies and projects.

Open Access This article is licensed under a Creative Commons Attribution 4.0 International License, which permits use, sharing, adaptation, distribution and reproduction in any medium or format, as long as you give appropriate credit to the original author(s) and the source, provide a link to the Creative Commons licence, and indicate if changes were made. The images or other third party material in this article are included in the article's Creative Commons licence, unless indicated otherwise in a credit line to the material. If material is not included in the article's Creative Commons licence and your intended use is not permitted by statutory regulation or exceeds the permitted use, you will need to obtain permission directly from the copyright holder. To view a copy of this licence, visit http://creativecommons.org/licenses/by/4.0/.

\section{References}

Adeabah, D., \& Andoh, C. (2020). Cost efficiency and welfare performance of banks: Evidence from an emerging economy. International Journal of Managerial Finance, 16(5), 549-574. https://doi. org/10.1108/IJMF-06-2019-0212.

Albuquerque, R., Koskinen, Y., \& Zhang, C. (2019). Corporate social responsibility and firm risk: Theory and empirical evidence. Management Science, 65(10), 4451-4469. https://doi.org/10.1287/ mnsc.2018.3043.

An, Q., Chen, H., Wu, J., \& Liang, L. (2015). Measuring slacks-based efficiency for commercial banks in China by using a two-stage DEA model with undesirable output. Annals of Operations Research, 235(1), 13-35.

Ariff, M., \& Can, L. (2008). Cost and profit efficiency of Chinese banks: a non-parametric analysis. China Economic Review, 19(2), 260-273.

Asmild, M., \& Matthews, K. (2012). Multi-directional efficiency analysis of efficiency patterns in Chinese banks 1997-2008. European Journal of Operational Research, 219(2), 434-441.

Avkiran, N. K., \& Morita, H. (2010). Benchmarking firm performance from a multiple-stakeholder perspective with an application to Chinese banking. Omega, 38(6), 501-508.

Bachelet, M. J., Becchetti, L., \& Manfredonia, S. (2019). The green bond premium puzzle: The role of issuer characteristics and third-party verification. Sustainability, 11, 1098.

Baker, M., Bergstresser, D., Serafeim, G., \& Wurgler, J. (2018). Financing the response to climate change: The pricing and ownership of U.S green bonds. NBER working paper no. 25194.

Banker, R. D., Charnes, A., \& Cooper, W. W. (1984). Some models for estimating technical and scale inefficiencies in data envelopment analysis. Management Science, 30(9), 1078-1092.

Bogetoft, P., \& Otto, L. (2011). Benchmarking with DEA, SFA, and R. Springer.

Bolton, B. (2013). Corporate social responsibility and bank performance. SSRN: https://ssrn.com/abstr act=2277912 or https://doi.org/10.2139/ssrn.2277912.

Breic, W., \& Kerstens, K. (2009). Infeasibility and directional distance functions with application to the determinateness of the Luenberger productivity indicator. Journal of Optimization Theory and Applications, 141(1), 55-73.

Briec, W., \& Leleu, H. (2003). Dual representations of non-parametric technologies and measurement of technical efficiency. Journal of Productivity Analysis, 20(1), 71-96.

Charnes, A., Cooper, W. W., \& Rhodes, E. (1978). Measuring the efficiency of decision-making units. European Journal of Operational Research, 2(6), 429-444.

Chen, X., Skully, M., \& Brown, K. (2015). Bank efficiency in China: Application of DEA to pre- and post-deregulation eras: 1993-2000. China Economic Review, 16(3), 229-245. 
Chortareas, G. E., Girardone, C., \& Ventouri, A. (2011). Financial frictions, bank efficiency and risk: Evidence from the Eurozone. Journal of Business Finance and Accounting, 38, 259-287.

Ciciretti, R., Kobeissi, N., \& Zhu, Y. (2014). Corporate social responsibility and financial performance: An analysis of bank community responsibility. International Journal of Banking, Accounting and Finance, 5(4), 342-372.

Dong, Y., Firth, M., Hou, W., \& Yang, W. (2016). Evaluating the performance of Chinese commercial banks: A comparative analysis of different types of banks. European Journal of Operational Research, 252(1), 280-295.

Du, K., Worthington, A. C., \& Zelenyuk, V. (2018). Data Envelopment Analysis, truncated regression and double-bootstrap for panel data with application to Chinese banking. European Journal of Operational Research, 265(2), 748-764.

Elliott, D., Kroeber, A., \& Qiao, Y. (2015). Shadow banking in China: A premier. The Brookings Institution.

Estelle, S. M., Johnson, A. C., \& Ruggiero, J. (2010). Three-stage DEA models for incorporating exogenous inputs. Computers and Operations Research, 37(6), 1087-1090.

Färe, R., \& Primont, D. (1995). Multi-output production and duality: Theory and applications. Kluwer Academic.

Francis, B., Harper, P., \& Kumar, S. (2018). The effects of institutional corporate social responsibility on bank loans. Business and Society, 57(7), 1407-1439.

Fu, T., Juo, J., Chiang, H., Yu, M., \& Huang, M. (2016). Risk-based decompositions of the meta profit efficiency of Taiwanese and Chinese banks. Omega, 62(July), 34-46.

Fukuyama, H., Guerra, R., \& Weber, W. L. (1999). Efficiency and ownership: Evidence from Japanese credit cooperatives. Journal of Economics and Business, 51(6), 473-487.

Fukuyama, H., \& Sekitani, K. (2012). Decomposing the efficient frontier of the DEA production possibility set into a smallest number of convex polyhedrons by mixed integer programming. European Journal of Operational Research, 221(1), 165-174.

Fukuyama, H., \& Weber, W. L. (2017). Measuring bank performance with a dynamic network Luenberger indicator. Annals of Operations Research, 250, 85-104.

Gambetta, N., Garcia-Benau, M. A., \& Zorio-Grima, A. (2017). Corporate social responsibility and bank risk profile: Evidence from Europe. Service Business, 11(3), 517-542.

Gangi, F., Mustilli, M., Varrone, N., \& Daniele, L. M. (2018). Corporate social responsibility and banks' financial performance. International Business Research, 11(10), 42-58.

Grosskopf, S., Hayes, K., Taylor, L., \& Weber, W. L. (1997). Budget constrained frontier measures of fiscal equality and efficiency in schooling. Review of Economics and Statistics, 79(1), 116-124.

Harjoto, M., \& Laksmana, I. (2016). The impact of corporate social responsibility on risk taking and firm value. Journal of Business Ethics, 151(2), 353-573.

Hassan, I., \& Marton, K. (2003). Development and efficiency of the banking sector in a transitional economy: Hungarian experience. Journal of Banking and Finance, 27, 2249-2271.

Hsu, F. J., \& Chen, Y. C. (2015). Is a firm's financial risk associated with corporate social responsibility? Management Decision, 53(9), 2175-2199.

Huang, M., \& Fu, T. (2013). An examination of the cost efficiency of banks in Taiwan and China using the metafrontier cost function. Journal of Productivity Analysis, 40(3), 387-406.

Jiang, C., Yao, S., \& Feng, G. (2013). Bank ownership, privatization, and performance: Evidence from a transition economy. Journal of Banking and Finance, 37(9), 3364-3372.

Kwan, S., \& Eisenbeis, R. A. (1997). Bank risk, capitalization and operating efficiency. Journal of Financial Services Research, 12, 117-131.

Liu, C., \& Song, W. (2004). A study on the efficiency of China's commercial bank based on SFA. Journal of Finance, 6, 138-142.

Mallin, C., Farag, H., \& Ow-Yong, K. (2014). Corporate social responsibility and financial performance in Islamic Banks. Journal of Economic Behaviour and Organization, 103(supplement), S21-S38.

Mcdonald, J. (2009). Using least square and Tobit in second stage DEA efficiency analyses. European Journal of Operational Research, 197(2), 792-798.

Oikonomou, I., Brooks, C., \& Pavelin, S. (2012). The impact of corporate social performance on financial risk and utility: A longitudinal analysis. Financial Management, 41(2), 483-515.

Olesen, O. B., \& Petersen, N. C. (1996). Indicators of ill-conditioned data sets and model misspecification in data envelopment analysis: an extended facet approach. Management Science, 42(2), 205-219.

Olesen, O. B., \& Petersen, N. C. (2003). Identification and use of efficient faces and facets in DEA. Journal of Productivity Analysis, 20(3), 323-360. 
Olesen, O. B., \& Petersen, N. C. (2015). Facet analysis in data envelopment analysis. In J. Zhu (Ed.), Data envelopment analysis: A handbook of models and methods (pp. 145-190). Springer.

Ouenniche, J., \& Carrales, S. (2018). Assessing efficiency profiles of UK commercial banks: A DEA analysis with regression-based feedback. Annals of Operations Research, 266, 551-587.

Partridge, C., \& Medda, F. R. (2020). The evolution of pricing performance of green municipal bonds. Journal of Sustainable Finance and Investment, 10, 44-64.

Platonova, E., Asutay, M., Dixon, R., \& Mohamad, S. (2018). The impact of corporate social responsibility disclosure on financial performance: evidence from the GCC Islamic Banking Sector. Journal of Business Ethics, 151(2), 451-471.

Schaeck, K., \& Cihak, M. (2014). Competition, efficiency and stability in banking. Financial Management, 43, 215-241.

Scholtens, B. (2009). Corporate Social Responsibility in the International Banking Industry. Journal of Business Ethics, 86(2), 159-175.

Shephard, R. W. (1970). Theory of Cost and Production Functions. Princeton University Press.

Shephard, R. W. (1974). Indirect Production Functions. Verlag Anton Hain.

Shi, X., Li, Y., Emrouznejad, A., Xie, J., \& Liang, L. (2017). Estimation of potential gains from bank mergers: A novel two-stage cost efficiency DEA model. Journal of the Operational Research Society, 68(9), 1045-1055.

Simar, L., \& Wilson, P. W. (2007). Estimation and inference in two-stage, semi-parametric models of production processes. Journal of Econometrics, 136(1), 31-64.

Simpson, W. G., \& Kohers, T. (2002). The link between corporate social and financial performance: Evidence from the banking industry. Journal of Business Ethics, 35(2), 97-109.

Soana, M. (2011). The relationship between Corporate Social Performance and Corporate Financial Performance in the Banking Sector. Journal of Business Ethics, 104(1), 133-148.

Song, Z., Zhang, Z., \& Yuan, M. (2009). DEA efficiency analysis of Chinese banking companies. Systems Engineering-Theory and Practice, 12, 2237-2243.

Sun, J., Harimaya, K., \& Yamori, N. (2013). Regional economic development, strategic investors and efficiency of Chinese city commercial banks. Journal of Banking and Finance, 37(5), 1602-1611.

Sun, L., \& Chang, T. (2011). A comprehensive analysis of the effects of risk measures on bank efficiency: Evidence from emerging Asian countries. Journal of Banking and Finance, 35(7), 1727-1735.

Tan, Y. (2016). The impacts of risk and competition on bank profitability in China. Journal of International Financial Markets, Institutions and Money, 40, 85-110.

Tan, Y. (2017). The impacts of competition and shadow banking on bank profitability: Evidence from the Chinese banking industry. The North American Journal of Economics and Finance, 42(November), 89-106.

Tan, Y., \& Floros, C. (2013). Risk, capital and efficiency in Chinese banking. Journal of International Financial Markets, Institutions and Money, 26, 378-393.

Tan, Y., \& Floros, C. (2018). Risk, competition and efficiency in banking: evidence from China. Global Finance Journal, 35, 223-236.

Tone, K. (2010). Variations on the theme of slacks-based measure of efficiency in DEA. European Journal of Operational Research, 200(3), 901-907.

Wang, B., \& Zhu, N. (2011). Efficiency and total factor productivity in listed commercial banks under the constraint of non-performing loans: an empirical analysis based on SBM directional distance function. Journal of Financial Research, 1, 23-42.

Wang, K., Huang, W., Wu, J., \& Liu, Y. (2014). Efficiency measures of the Chinese commercial banking system using an additive two-stage DEA. Omega, 44(April), 5-20.

$\mathrm{Xu}, \mathrm{X}$., \& Shi, P. (2006). Efficiency comparative study on commercial bank in China based on DEA and SFA. Application of Statistics and Management, 1.

Yang, D., \& Zhang, A. (2007). The efficiency evaluation of China's commercial banks from 1996 to 2005. Journal of Financial Research, 12.

Yao, S., Feng, G., \& Jiang, C. (2004). The empirical analysis of efficiency of Chinese banks. Economic Research Journal, 8.

Yildirim, C. (2002). Evolution of bank efficiency within an unstable macroeconomic environment: the case of Turkish commercial banks. Applied Economics, 34, 2289-2301.

Yu, A., Shao, Y., You, J., Wu, M., \& Xu, T. (2019). Estimations of operational efficiencies and potential income gains considering the credit risk for China's banks. Journal of the Operational Research Society, 70(12), 2153-2168.

Zha, Y., Liang, N., Wu, M., \& Bian, Y. (2016). Efficiency evaluation of banks in China: A dynamic twostage slacks-based measure approach. Omega, 60(April), 60-72. 
Zhou, X., Xu, Z., Chai, J., Yao, L., Wang, S., \& Lev, B. (2018). Efficiency evaluation for banking systems under uncertainty: A multi-period three-stage DEA model. Omega, 85(June), 68-82.

Zhu, N., Stjepcevic, J., Balezentis, T., Yu, Z., \& Wang, B. (2017). How does corporate social responsibility impact banking efficiency: A case of China. E a M: Ekonomie a Management, 20(4), 70-87.

Publisher's Note Springer Nature remains neutral with regard to jurisdictional claims in published maps and institutional affiliations. 